\title{
RELAÇÃO PORTO E CIDADE: ESTUDO DE IMPACTO DE VIZINHANÇA NAS INSTALAÇÕES PORTUÁRIAS DA CIDADE DE SANTOS/SP
}

\section{PORT AND CITY: STUDY OF THE IMPACT ON NEIGHBORHOOD OF PORT FACILITIES IN THE CITY OF SANTOS/SP}

\author{
${ }^{1}$ Rhiani Salamon Reis Riani \\ ${ }^{2}$ Allexandre Guimaraes Trindade
}

\section{RESUMO}

O presente trabalho visa demonstrar a exigência do Estudo de Impacto de Vizinhança para a licença e autorização de construção, ampliação ou funcionamento de Instalações Portuárias no município de Santos/SP. Previsto no Estatuto da Cidade, o EIV é uma ferramenta de controle, cuja regulamentação é de exclusividade dos municípios brasileiros, conforme os artigos 36 e 37 da Lei n.10.257/01. O município de Santos é uma cidade portuária que, pelas instalações portuárias, sofre todos os tipos de impactos possíveis, sendo eles positivos e negativos. A Lei n. 10.257/01 regula o uso da propriedade urbana a favor do bem social coletivo, com o fito de garantir a sustentabilidade das cidades. Para alcançar os objetivos deste artigo será adotada a abordagem epistemológica positivista e o médodo de abordagem dedutivo, para analisar dispositivos legais inerentes ao Estudo de Impacto de Vizinhança em empreendimentos portuários no Município de Santos. Nesse sentido, pretende-se estudar a aplicação do Estudo de Impacto de Vizinhança nos empreendimentos portuários localizados na cidade de Santos e a sua relação com o desenvolvimento socioeconômico do município, conforme exigência da Lei Complementar municipal $n^{\circ}$ 793/2013. As técnicas de delineamento adotadas foram pesquisa documental, jurídica e bibliográfica.

Palavras-chave: Estudo de impacto de vizinhança, Instalações portuárias, Município de santos

\footnotetext{
${ }^{1}$ Mestrando em Direito pela Universidade Católica de Santos - UNISANTOS, São Paulo (Brasil)

E-mail: $\underline{\text { rhiani@uol.com.br }}$

${ }^{2}$ Mestrando em Direito pela Universidade Católica de Santos - UNISANTOS, São Paulo (Brasil). Sócio Administrador em Guimarães Advogados Associados, São Paulo (Brasil).

E-mail: allexandre.gadv@gmail.com
} 


\begin{abstract}
The purpose of this article is to demonstrate the need for the Study of the Impact of Neighborhood for (SIN) the license and authorization for construction, expansion or operation of Port Facilities in the city of Santos/SP. Due to the Statute of the City, the SIN is a tool of control, whose regulation is of exclusivity of Brazilian municipalities, according to the articles 36 and 37 of Law no. 10.257/01. The city of Santos is a port city that, by port facilities, suffering from all kinds of possible impacts, and they were both positive and negative. The Law no 10.257/01 regulates the use of urban property in favor of social and collective, with the aim of ensuring the sustainability of cities. To achieve the objectives of this Article shall be adopted the method of approach positivism, as it will be analyzed the legal devices inherent in the Study of the Impact of Neighborhood ventures in port in the City of Santos. In this sense, it is intended to examine the application of the Study of the Impact of Neighborhood ventures in port located in the city of Santos and its relationship with the socioeconomic development of the municipality, according to the requirements of Complementary County Law no. 793/2013.
\end{abstract}

Keywords: Study of the impact of neighborhood, Port facilities, Municipality of santos 


\section{INTRODUÇÃO}

$\mathrm{O}$ auge da história da humanidade ocorreu no momento em que o homem se lançou ao mar e passou a navegar para terras distantes. Foram pelas navegações que grandes impérios se formaram e grandes civilizações emergiram.

Décadas e séculos se passaram, e a navegação, ainda, continua sendo o meio de transporte mais importante da humanidade, contribuindo para fomentação da economia e o progresso do comércio internacional.

Foram diante de portos que grandes cidades acenderam e grandes civilizações se formaram. No Brasil não foi diferente. Os portos brasileiros sempre desempenharam papel relevante no desenvolvimento econômico, desde o período colonial até os dias atuais (DE SOUZA, 2011, p. 212).

A cidade de Santos ascendeu diante do Porto de Santos e de outros terminais portuários. Por isso, faz se necessário que o poder público municipal promova uma política pública capaz de fomentar uma relação harmoniosa entre o Porto e a Cidade.

Para promover um bem-estar para os cidadãos, o desenvolvimento e a sadia qualidade de vida nos centros urbanos, o legislador brasileiro colocou em vigência o Estatuto da Cidade, Lei n. 10.257/01. Este estatuto estabelece diretrizes gerais e instrumentos para promover o equilíbrio do ambiente urbano.

Dentre os instrumentos dispostos, encontra-se o Estudo de Impacto de Vizinhança (EIV). Considerando que as instalações portuárias encontra-se ligada a cidade de Santos e, por consequência, também, com os cidadãos santistas, pretende-se, neste trabalho, verificar se o Município de Santos exige o Estudo de Impacto de Vizinhança para a licença ou autorização de construção, ampliação ou funcionamento de empreendimentos portuários (instalações portuárias).

Para o desenvolvimento deste trabalho será adotado o Método de abordagem positivismo, haja vista que serão analisados os dispositivos legais inerentes ao Estudo de Impacto de Vizinhança em empreendimentos portuários no Município de Santos. Quanto à técnica procedimental, utilizar-se-á da pesquisa bibliográfica e documental, uma vez que se fez necessário pesquisar na doutrina aspectos relacionados ao estudo de impacto de vizinhança (EIV) e na legislação urbanística federal e municipal santista, os dispositivos legais referentes ao Estudo de Impacto de Vizinhança.

Neste sentido, o Capítulo 01 (um), cuidar-se-á de demonstrar a Relação Porto e Cidade: a sustentabilidade nos portos. No Capítulo 02 (dois), pretende-se apresentar o 
estudo de impacto de vizinhança (EIV), como um instrumento de política pública. No Capítulo 03 (três), examinar-se-á a exigência de Estudo de Impacto de Vizinhança nas instalações portuárias da Cidade de Santos. Por fim, é apresentada a conclusão deste trabalho.

\section{RELAÇÃO PORTO E CIDADE: A SUSTENTABILIDADE NOS PORTOS}

O vocábulo desenvolvimento é por diversas vezes mencionado em nossa Constituição de 1988 (preâmbulo; art. 3º, inc. III; art. 174; art. 192; art. 205; art. 218; art. 219). O desenvolvimento foi tratado pelo Constituinte Originário como um valor supremo, que necessariamente, sob uma analise sistemática e teleológica da Constituição da República Federativa do Brasil de 1988, pensa-se em sustentabilidade.

O professor Juarez Freitas (2011, p.113) afirma que

"Sustentabilidade, em nosso sistema jurídico-político, é, entre valores, um valor constitucional supremo, desde que adotada a releitura da Carta endereçada à produção de homeostase biológica e social de longa duração."

Considerado como um valor supremo, a sustentabilidade deverá ser um norte nas políticas públicas do Estado, na gestão dos entes privados, bem como nos afazeres cotidianos dos cidadãos brasileiros. A sua carga axiológica, faz com que a sustentabilidade tenha um valor pluridimensional (ética, social, econômico, jurídico- política e ambiental).

A Agenda 21 Brasileira, um programa de proteção ambiental para o século XXI, definida na Conferência do Rio de Janeiro de 1992 (GRANZIERA, 2014, p. 52), afirma que o desenvolvimento sustentável é um conceito que está em construção. Por isso, conforme assevera o doutrinador José Eli da Veiga (2010, p. 189),

“[...] os princípios e premissas que poderão orientar a sua implementação ainda são experimentais, e que dependem, antes de tudo, de um processo social, no qual os atores deverão pactuar, aos poucos, os novos consensos de uma agenda possível, rumo ao futuro que se deseja sustentável".

Deste modo, percebe-se que o desenvolvimento sustentável é um principio, valor supremo consagrado, almejado pelo Sistema Constitucional Brasileiro. Com isso, 
toda e qualquer atividade humana deve ser exercida da maneira mais sustentável possível assegurando, hoje, o bem-estar físico, psíquico e espiritual, sem inviabilizar o multidimensional bem-estar futuro (FREITAS, 2011, p. 41).

Sendo um empreendimento de interesse público (político, social e econômico) deve-se planejar e visualizar a atividade portuária de uma forma que não seja prejudicial ao meio ambiente natural ou artificial (cidades) e, por conseguinte, a saúde e o bemestar do homem.

Assevera Ingrid Zanella (Apud. SILVA, 2013, p. 447).

“[...] os portos e as instalações portuárias não obstante proporcionaram benefícios socioeconômicos constituem empreendimentos que ocasionam impactos ambientais significativos ao meio ambiente, desde a construção e implantação de suas instalações, até o funcionamento de suas atividades”.

Apesar da nova Lei dos Portos (Lei n. 12.815/2013) não dispor de maneira incisiva a defesa do meio ambiente das cidades como uma diretriz, a referida lei apresenta o desenvolvimento do País como um objetivo da norma, assim, por hermenêutica jurídica, pressupõe o desenvolvimento sustentável.

Mesmo com a falta de disposição expressa da nova Lei (n. 12.815/2013), o ordenamento jurídico ambiental portuário e os órgãos regulamentadores do meio ambiente portuário (ANTAQ, SEP, ANVISA e outros) são taxativos ao traçar a necessidade de harmonia entre o desenvolvimento econômico e social do País com a proteção do meio ambiente natural e artificial (cidades).

Com isso, o licenciamento se faz um importante instrumento para a promoção do desenvolvimento sustentável das instalações portuárias. Todavia, este instrumento da Política Nacional do Meio Ambiente (Lei 6.938/81) não deve ser utilizado de forma singular.

O escopo almejado pela referida Política somente será alcançado se os entes públicos se utilizarem do licenciamento e suas exigências especificas, em consonância com os outros instrumentos dispostos no artigo $9^{\circ}$, da Lei 6.938/81 (Política Nacional do Meio Ambiente) e no artigo $4^{\circ}$, da Lei 10.257/01 (Estatuto das Cidades).

Os entes federativos licenciadores, na análise técnica das requisições de licenciamento para instalações portuárias, devem considerar os Planos Nacionais e Estaduais de Gerenciamento Costeiro, os Zoneamentos Ecológico-Econômico, a 
Avaliação Ambiental Estratégica, os Planos Diretores Municipais e outros instrumentos postos a defesa do meio ambiente natural e das cidades.

É diante da necessária junção entre a atividade portuária e da proteção do meio ambiente que surge o Direito Ambiental Portuário, que segundo a doutrinadora Ingrid Zanella (Apud SILVA, 2013, p. 450),

“O Direito Ambiental Portuário pode ser entendido como o conjunto de normas jurídicas ambientais (preventiva e repressiva) que incidem sobre a instalação, operacionalização e funcionamento do porto, com vistas à consecução dessas atividades nos limites de capacidade do meio ambiente, prevenindo a ocorrência de danos ambientais".

Dentro do Direito Ambiental Portuário que se insere o licenciamento ambiental portuário, composto por seus planos e programas ambientais, e outros instrumentos necessários e obrigatórios para a concessão da licença de instalação e operação do empreendimento portuário.

Todas as instalações portuárias, independente de estarem localizadas dentro ou fora da área do Porto Organizado, deverão seguir todas as normas editadas pelos entes responsáveis pela regulação e fiscalização das atividades portuárias, com especial atuação da Agência Nacional de Transportes Aquaviários (ANTAQ), Agência Nacional de Vigilância Sanitária (ANVISA), Receita Federal, órgãos ambientais (federal, estadual, ou municipal) e Capitania dos Portos.

Além do Direito Ambiental Portuário, também existe o Direito das Cidades Portuárias. O Direito das Cidades Portuárias pode ser entendido como o conjunto de normas jurídicas (preventiva e repressiva) que incidem sobre a instalação, operacionalização e funcionamento do porto, com vistas à consecução dessas atividades nos limites de capacidade das cidades, prevenindo a ocorrência de danos ao bem-estar dos cidadãos, bem como do equilíbrio ambiental, conforme diretrizes do Estatuto das Cidades e das legislações municipais de regulação do solo e posturas.

Todos os portos que se encontram nos limites das cidades brasileiras devem respeitar os ditames estabelecidos no Estatuto das Cidades e nas leis municipais.

A política portuária deve coexistir com a política urbana para garantir o direito a cidades sustentáveis, entendido como o direito à terra urbana, à moradia, ao saneamento ambiental, à infra-estrutura urbana, ao transporte e aos serviços públicos, ao trabalho e ao lazer, para as presentes e futuras gerações (art. $2^{\circ}$, I, da Lei 10.257/01) 
O desenvolvimento econômico em harmonia com o meio ambiente natural e artificial pressupõe um desenvolvimento sustentável, viabilizando a existência de cidades sustentáveis para as atuais e futuras gerações (GILBERTONI, 2005, p. 379).

Diante das considerações apresentadas, conclui-se que atividade portuária, assim, como as outras atividades econômicas devem coexistir de forma fraterna com o meio ambiente das cidades, para promover o pleno desenvolvimento almejado pela República Federativa o Brasil.

\section{O ESTUDO DE IMPACTO DE VIZINHANÇA COMO INSTRUMENTO DE DESENVOLVIMENTO SUSTENTÁVEL}

A crescente urbanização da humanidade, que ocorreu de forma desordenada, colaborou para a necessidade de criação de disciplinas de organização e planejamento do espaço urbano. É com a necessidade de se planejar e disciplinar as cidades que surge o Direito Urbanístico.

Hely Lopes Meirelles (2014, p. 533) conceitua o direito urbanístico como “[...] o conjunto de medidas estatais destinadas a organizar os espaços habitáveis, de modo a propiciar melhores condições de vida ao homem na comunidade".

No Brasil, o Direito Urbanístico, apesar dos artigos 182 e 183 da CRFB/88, só ganha força com a vigência do Estatuto da Cidade, Lei 10.257/01. O Estatuto da Cidade é o conjunto normativo responsável por estabelecer normas gerais de ordem pública e interesse social que regulam o uso da propriedade urbana em prol do bem coletivo, da segurança e do bem-estar dos cidadãos, bem como do equilíbrio ambiental (art. $1^{\circ}$, parágrafo único, da Lei 10.257/01).

Sendo uma legislação de política urbana, o Estatuto da Cidade visa ordenar o pleno desenvolvimento das funções sociais da cidade e da propriedade urbana, com o objetivo de promover o bem estar coletivo (art. $2^{\circ}$, caput, da Lei 10.257/01).

A execução de políticas públicas deve ser precedida da elaboração de instrumentos necessários para ordenar as atividades e necessidades de cada espaço territorial, planejando as ações locais (municipais) e regionais (metropolitanas e microrregionais).

O processo de planejamento é mais importante que os planos e instrumentos propriamente ditos, pois, para alcançar os objetivos almejados, deve abranger todos os setores envolvidos na prestação de serviços e estar adequado à realidade local, 
harmonizando políticas, planos e programas setoriais, com ampla participação popular (SILVA, 2012).

Assim, para promover a política urbana sustentável, a Lei 10.257/01 criou diversos instrumentos de gestão, disciplina e planejamento do espaço urbano, dentre eles, destaca-se, o Estudo de Impacto de Vizinhança (EIV).

Cyntia da Silva Almeida Willeman (2007) define o Estudo de Impacto de Vizinhança como um "documento técnico que deve ser elaborado previamente à emissão das licenças ou autorizações de construção, ampliação ou funcionamento de empreendimentos privados ou públicos em área urbana".

Previsto no artigo $4^{\circ}$, inciso VI, do Estatuto da Cidade, o Estudo de Impacto de Vizinhança é um instrumento de política urbana indispensável a concessão de licenças ou autorizações de construção, ampliação ou funcionamento de empreendimentos privados ou públicos em área urbana.

O EIV representa o mandamento constitucional presente no inciso XXIII, do art. $5^{\circ}$, da CRFB/88, qual seja: "a propriedade atenderá a sua função social”. A axiologia disposta na cláusula pétrea constitucional exige que o proprietário desfrute de seu direito de modo fraterno, não de maneira egoísta, pensando na vizinhança, ou melhor, na coletividade.

Com a vigência do Estado Democrático de Direito Ambiental, amparado pelo Constituição Federal de 1988, o direito de propriedade só será sustentável quando atender a sua função socioambiental. Para a ordem constitucional atual, apenas será reconhecida a propriedade que respeita o meio ambiente (natural e artificial) e o bemestar geral.

José dos Santos Carvalho Filho (2013, p. 306) afirma que "o condicionamento do direito de propriedade à função social demonstra que o direito constitui um instrumento jurídico conferido ao particular, mas posto a serviço da coletividade”.

Para fomentar o uso socioambiental da propriedade, o ordenamento jurídico brasileiro armou o Poder Público de instrumentos jurídicos de controle ao egoísmo. Dentre os instrumentos, encontra-se o Estudo de Impacto de Vizinhança (EIV).

O EIV é um instrumento de política urbana. Deste modo, quem, dentre os entes políticos da federação, lida e conhece melhor as dificuldades das cidades? A resposta não poderia ser outra, o Município. O ente federativo responsável, segundo a Constituição de 1988 (art. 30, I), por legislar sobre assuntos de interesse local. 
Portanto, caberá ao ente municipal, mediante lei, determinar quais os empreendimentos e atividades privadas ou públicas em área urbana dependerão de elaboração prévia do Estudo de Impacto de Vizinhança (EIV), conforme dispõe o artigo 36, caput, da Lei 10. 257/01 (Estatuto da Cidade).

Ao exigir o EIV, a municipalidade busca harmonizar interesses conflitantes, que são, de um lado, o interesse na realização de construções e, de outro, o interesse daqueles que, por sua proximidade, são suscetíveis de sofrer algum tipo de turbação daquelas (CARVALHO FILHO, 2013, p. 310).

O Estatuto da Cidade, segundo o art. 37, elencou quais questões deverão ser contempladas no EIV. Segundo Hely Lopes Meirelles (2014, p. 556):

"O EIV será executado de forma a contemplar os efeitos positivos e negativos do empreendimento ou atividade quanto á qualidade de vida da população residente na área e suas proximidades, incluindo a análise, no mínimo, dos itens seguintes: adensamento populacional; equipamentos urbanos e comunitários; uso e ocupação do solo; valorização imobiliária; geração de tráfego e demanda por transporte público; ventilação e iluminação; paisagem urbana e patrimônio natural e cultural".

Conforme o artigo 37, do Estatuto da Cidade, no EIV deverá conter, no mínimo, as seguintes questões:

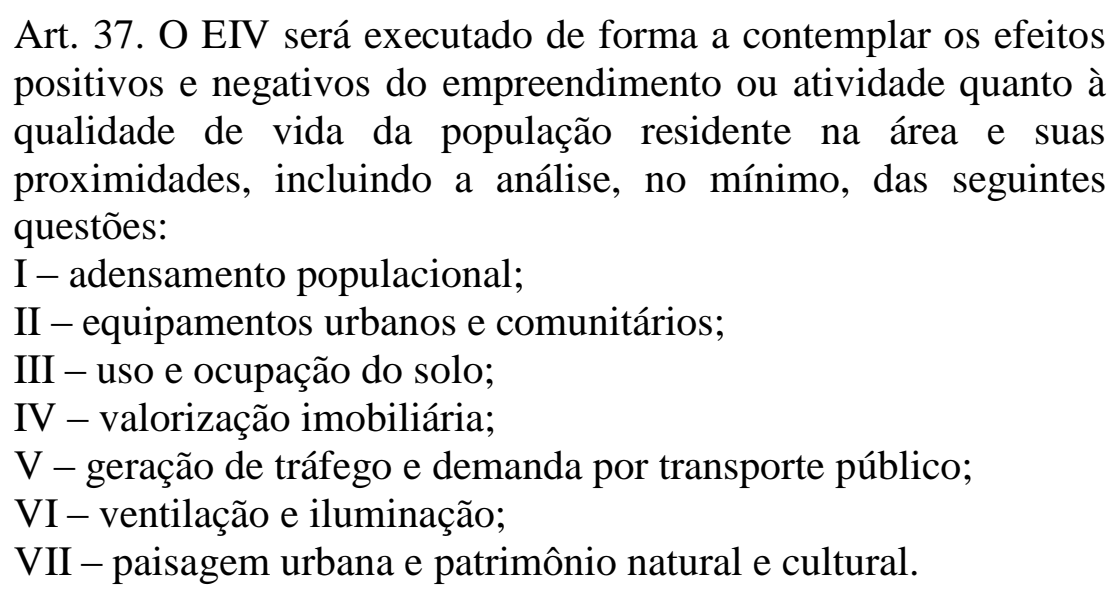

O EIV não está limitado a um estudo teórico. Sua característica principal é a técnica, uma vez que sua elaboração deverá ser feita por profissionais qualificados, nos termos do artigo 37. Analises estatísticas, mapeamento de área, situação fundiária, caracterização do solo, mitigação de impactos, impactos na mobilidade, pesquisas de 
mercado, são questões que, dependendo do empreendimento, serão analisadas e apresentadas no estudo, um importante documento público realizado a serviço da coletividade.

É um estudo multidisciplinar, pois abarca questões da geografia, biologia, matemática, economia e outras. Esta multidisciplinaridade representa a busca pela garantia do direito a cidades sustentáveis e a gestão democrática da cidade.

O Estudo de Impacto de Vizinhança (EIV) apresenta os impactos causados por empreendimentos e atividades urbanas, devendo cada município prever as hipóteses de sua obrigatoriedade e regulamentar as informações que delimitarão as avaliações a serrem tomadas pelo município.

Trata-se de um instrumento contemporâneo, que atende às exigências da vida moderna e que está integrado ao direito urbanoambiental, que tem sua matriz no cumprimento da função social da propriedade. A partir da análise dos impactos é possível avaliar a pertinência da implantação do empreendimento ou atividade no local indicado, ou seja, avaliar se o proposto está adequado ao local, estabelecendo uma relação da cidade com o empreendimento e do empreendimento com a cidade, considerando o meio no qual está inserido.

Além disso, a partir da avaliação de impactos é possível apontar formas de mitigação do impacto gerado, ou seja, minoração dos efeitos do empreendimento ou atividade no meio urbano, além de medidas compensatórias para o mesmo meio no qual a atividade ou empreendimento se instalará (PRESTES, 2005).

O Estudo de Impacto de Vizinhança (EIV) é mais um instrumento de gestão previsto para avaliação de impactos urbanos de atividades e empreendimentos a serem instalados no município, com características similares ao EIA, porém não o substitui (art. 38, Estatuto da Cidade) (PRESTES, 2005).

Enquanto instrumento de gestão, o EIV deve direcionar a tomada de decisão do gestor público, o qual deverá considerar todos os elementos colocados no estudo, não havendo obrigatoriedade de vinculação ao mesmo, desde que a decisão seja motivada e justificada (PRESTES, 2005).

Embora o Estatuto da Cidade não tenha previsão expressa de realização de audiência pública quando da elaboração do EIV, na sua regulamentação, os municípios podem e devem prever a hipótese de realização de audiência pública e outras formas de publicização do estudo, haja vista ser fundamental a participação popular no processo de tomada de decisão (PRESTES, 2005). 
A Administração Pública não está vinculada às questões e decisões da audiência pública, até porque podem ser contraditórias, devendo enfrentar as intervenções populares apresentadas nas audiências para motivar a sua decisão.

A gestão democrática das cidades, imposta pelo Estatuto das Cidades e adotada pela Agenda 21 Brasileira no enfrentamento da deterioração ambiental dos espaços urbanos por meio da participação popular de todos os segmentos da sociedade, é fundamental para formular, executar e acompanhar os planos, programas e projetos municipais de desenvolvimento urbano (PADILHA, 2010).

O grande desafio da gestão de políticas em territórios metropolitanos é gerar ações integradas de desenvolvimento urbano, transformando o território político em território funcional, com efetivos resultados de melhoria da qualidade de vida (MARTINS, 2015).

Quando apresentado o EIV, a Administração Pública Municipal realizará uma avaliação. Após sua analise, pelo principio da informação (art. 37, caput, da CRFB/88), deverão tornar-se publico os documentos integrantes do EIV, que ficarão disponíveis para consulta, no órgão competente do Poder Público municipal, para qualquer interessado.

Além disso, é importante destacar a influencia do Plano Diretor ${ }^{1}$ no EIV, ao definir os parâmetros de crescimento das cidades, com o objetivo de promover um bemestar social de qualidade nas cidades. Todos os instrumentos de política urbana devem ser efetivados em consonância mútua.

Desta feita, cada município deve criar uma lei para regulamentar o instituto jurídico do estudo de impacto de vizinhança, mas é importante resaltar que os municípios precisam respeitar os ditames do Estatuto da Cidade e da Constituição Federal de 1988.

\section{O ESTUDO DE IMPACTO DE VIZINHANÇA NO LICENCIAMENTO AMBIENTAL DE INSTALAÇÕES PORTUÁRIAS NO MUNICÍPIO DE SANTOS}

\footnotetext{
${ }^{1}$ No tocante ao Plano Diretor Urbano, MUKAI (2001, p. 33) discorre como: "Instrumento legal que visa propiciar o desenvolvimento urbano (portanto, da cidade) do Município, fixando diretrizes objetivas (metas), programas e projetos para tanto, em horizonte de tempo determinado".
} 
O Comércio marítimo foi fundamental para o desenvolvimento de diversas cidades ao redor do Planeta. Assim, o mar tornou-se um elemento da natureza imprescindível ao desenvolvimento, sobrevivência e ao poder de diversas cidades (MARTINS, 2013, p. 01). É neste contexto que surgem os portos.

O crescimento do Município de Santos se confunde com a história de seu Porto, um gigante responsável por cerca de $26 \%$ (vinte seis por cento) da balança comercial brasileira (Prefeitura de Santos, 2015).

O desenvolvimento de toda a região santista e as transformações de seu principal porto (Porto de Santos), com suas reorganizações contínuas, foram processos marcadamente interligados. A Cidade e o Porto de Santos de confundem, uma vez que este subjugou a região, a impondo mudanças (GONÇALVES; NUNES, 2008, p.08)

Santos é uma cidade predominantemente portuária. Seus cidadãos, desde os tempos do Brasil colonial, convivem diretamente com os efeitos positivos e negativos que o porto de Santos ocasiona a cidade. Os santistas não só coexistem com o porto, mas também com as demais instalações portuárias, terminais privativos, que circundam o município.

É certo que a atividade portuária causa efeitos positivos a cidade (geração de emprego e renda), mas também causa efeitos negativos, como por exemplo, o acidente ocorrido na área industrial da Alemoa, no Terminal da Ultracargo, que é responsável pelo armazenamento de graneis líquidos (ULTRACARGO, 2015).

Toda atividade econômica que se encontra em área urbana, necessariamente, estará subordinada aos preceitos da Lei 10.257/01, o Estatuto da Cidade. Esta subordinação dependerá de Lei Municipal que disciplinará as licenças e autorizações para construção, ampliação ou funcionamento.

A Lei Municipal, nos termos do artigo 36, caput, do Estatuto da Cidade, que definirá os empreendimentos e atividades privados ou públicos em área urbana que dependerão de elaboração de estudo prévio de impacto de vizinhança (EIV).

No caso do Município de Santos, a Lei Complementar n 793 de 14 de janeiro de 2013, que disciplina a exigência do estudo prévio de impacto de vizinhança - EIV, e cria o atestado de conformidade de infraestrutura urbana e ambiental no âmbito do município.

Segundo dispõe a Lei Complementar no 793/2013, o EIV tem por objetivo: 
“[...] objetivo permitir que a implantação de empreendimentos ou atividades geradoras de impactos garanta a qualidade de vida da população residente na área e em suas proximidades, conforme preconiza a Lei Federal $\mathrm{n}^{\mathrm{o}} 10.257$, de 10 de julho de

2001 - Estatuto da Cidade e o Plano Diretor de Desenvolvimento e Expansão Urbana do Município, instituído pela Lei Complementar $n^{\circ} 731$, de 11 de julho de 2011".

Os empreendimentos econômicos sujeitos ao Estudo Prévio de Impacto Ambiental (EIV) estão dispostos no ANEXO I da Lei Complementar no 793/2013.

Estas atividades econômicas deverão apresentar o Estudo de Impacto Ambiental (EIV) ao órgão competente do município, que encaminhará a Comissão Municipal de Análise de Impacto de Vizinhança - COMAIV, regulamentada pelo Decreto N. 6.401 de 07 de maio de 2013. A referida Comissão analisará o estudo e apresentará sua manifestação pela aprovação ou não do mesmo.

Os empreendimentos dispostos no ANEXO I da Lei Complementar $\mathrm{n}^{\circ}$ 793/2013 são obrigados a apresentar o Estudo de Impacto de Vizinhança (EIV). Considerando que Atividades portuárias e retroportuárias permitidas nas zonas portuárias e retroportuárias (ATT > $20.000 \mathrm{~m}^{2}$ ) estão previstas no supracitado anexo, então, conclui-se que no município de Santos as instalações portuárias estão sujeitas, em casos de licenças e autorizações, a apresentação do EIV.

A Lei 12.815/2013 (novo marco regulatório dos portos) prezou pela definição, no seu artigo $2^{\circ}$, de seus instrumentos de trabalho, dentre eles, o termo instalação portuária, presente no inciso III, do referido artigo:

Art. $2^{\circ}$, III - instalação portuária: instalação localizada dentro ou fora da área do porto organizado e utilizada em movimentação de passageiros, em movimentação ou armazenagem de mercadorias, destinadas ou provenientes de transporte aquaviário;

Marcos Maia Porto e Sérgio Grein Teixeiras (2001, p. 64/65), sobre instalações portuárias, conceitua como:

"As instalações portuárias são o conjunto de elementos construídos em terra e em mar que compõem a arquitetura física dos portos, possibilitando dentro de um determinado perfil da instalação o adequado atendimento à carga. [...]. As instalações portuárias consistem no conjunto de edificações e obras em terra 
ou em mar para acostagem, como cais, piers, dolfins, para armazenagem como pátios, silos; para circulação como canais de acesso, bacias de evolução, linhas férreas, rodovias e etc.".

Na Lei 12.815/13, o termo instalação portuária é o gênero das espécies: i) instalações portuárias localizadas dentro do porto organizado, alcançadas mediante concessões, arrendamento e por convênio de delegação; e ii) instalações portuárias localizadas fora da área do porto organizado, alcançadas por autorização do poder concedente.

É evidente que, as instalações portuárias, pela natureza de suas atividades, quanto maiores forem, maiores serão as interferências ou modificações no ambiente urbano.

Exigir o EIV dos empreendimentos portuários significa colocar a sustentabilidade na pauta do desenvolvimento municipal. Não representa um entrave para o progresso, mas um fomento ao verdadeiro progresso, que é o desenvolvimento sustentável, aquele que visa primordialmente a sadia qualidade de vida dos cidadãos.

Com relação ao EIA (Estudo de Impacto Ambiental) e o EIV, é importante destacar que, conforme o artigo 37, VII, do Estatuto da Cidade, o EIV também investiga questões relacionadas ao patrimônio natural, que significa o meio ambiente. Por isso, nada impede que um município exija ambos os estudos, todavia, para se evitar duplicidade e burocracia exageradas, pode apenas o EIV contemplar a investigação de impacto ambiental (CARVALHO FILHO, 2013, p. 329).

O Município de Santos, ao exigir o EIV dos empreendimentos portuários, não só coloca em sua política urbana a eficiência e eficácia dos ditames constitucionais e do Estatuto das Cidades, mas também torna a cidade de Santos um lugar de qualidade de vida e de equilíbrio urbano.

\section{CONCLUSÃO}

O Estudo de Impacto de Vizinhança (EIV) é um instrumento de política urbana disposto no Estatuto da Cidade, Lei n. 10.257/01. Contudo, para sua efetivação, a infraconstitucional supracitada, concedeu aos Municípios o dever de regulamentar este importante instrumento de disciplina dos empreendimentos em espaços urbanos. 
O Município de Santos, em respeito à legislação federal, e preocupado com a qualidade de seu ambiente urbano, regulamentou o Estudo de Impacto de Vizinhança por intermédio da Lei Complementar $n^{\circ} 793 / 2013$.

A referida Lei Complementar municipal dispôs, em seu ANEXO I, todas as atividades e empreendimento econômicos obrigados a apresentar Estudo de Impacto de Vizinhança ao poder público municipal. Dentre estes empreendimentos encontram-se as instalações portuárias (Atividades portuárias e retroportuárias permitidas nas zonas portuárias e retroportuárias - ATT > $20.000 \mathrm{~m}^{2}$ ).

Sendo empreendimentos com grande capacidade impactante, os empreendedores, que almejarem licenças ou autorizações para instalações portuárias, deverão apresentar ao órgão competente da Prefeitura de Santos o Estudo de Impacto de Vizinhança. Este estudo, por imperativo do Decreto N. 6.401 de 07 de maio de 2013, será encaminhado a Comissão Municipal de Análise de Impacto de Vizinhança COMAIV, que dará o parecer final pela procedência ou não do estudo.

Por questões históricas, econômicas e políticas, um dos maiores portos do Brasil ainda encontra-se na Cidade de Santos, o Porto de Santos. As atividades portuárias e marítimas são as bases da economia santista. Com isso, faz se necessário que o poder público municipal promova políticas públicas que visem à criação de uma harmonia entre o porto e a cidade santista. O EIV torna-se um instrumento de busca por essa harmonia. Todavia, ressalta-se que o EIV será exigível se o empreendedor não contemplar questões de impacto urbanístico no Estudo de Impacto Ambiental (EIA).

Ao exigir o EIV, a Prefeitura de Santos estará promovendo a garantia do direito a cidades sustentáveis, o planejamento desenvolvimentista, o bem-estar dos cidadãos e a sadia qualidade do meio ambiente urbano para as presentes e futuras gerações.

\section{REFERÊNCIAS}

BRASIL. Lei 10.257, de 10 de julho de 2001. Estatuto da Cidade. Disponível em: http://www.planalto.gov.br/ccivil_03/leis/LEIS_2001/L10257.htm. Acesso em: 08 jul. 2015.

$$
\text { Lei n. } \quad \mathbf{1 2 . 8 1 5 / 2 0 1 3} \text {. Disponível em: }
$$

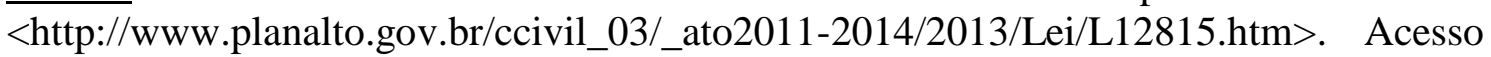
em: 06 jul. 2015. 
. Lei n. $\quad$ 10.257/01. Disponível em:

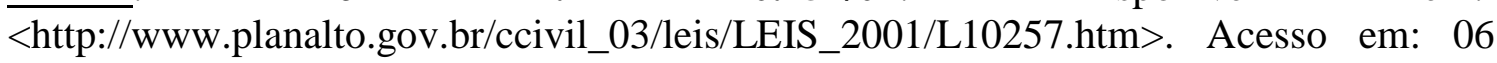
jul. 2015.

CARVAlHO FILHO, José dos Santos. Comentários ao Estatuto da Cidade. 5 ed. São Paulo: Atlas, 2013.

DE SOUZA, Maria Cláudia da Silva Antunes. Os portos brasileiros e seus gargalos frente às novas necessidades: especial referencia à gestão. Direito Portuário, Regulação e Desenvolvimento. Coordenadores: Osvaldo Agripino de Castro Jr., Cesar Luiz Pasold. 2 ed. Belo Horizonte: Fórum, 2011, p. 212.

FREITAS, Juarez. Sustentabilidade: direito ao futuro. $1^{\mathrm{a}}$ ed. Belo Horizonte: Fórum, 2011.

GIBERTONI, Carla Adriana Comitre. Teoria e prática do direito marítimo. Rio de Janeiro: Renovar, 2005.

GONÇALVES, Alcindo; NUNES, Luiz Antonio de Paula. O Grande Porto: A modernização no porto de Santos. Santos, SP: Realejo Edições, 2008.

GRANZIERA, Maria Luiza Machado. Direito Ambiental. $3^{a}$ ed. São Paulo: Editora Atlas S.A, 2014.

MEIRELLES, Hely Lopes. Direito Municipal Brasileiro. 17 ed. São Paulo: Malheiros Editores, 2014.

MARTINS, Maria Lucia Refinetti. Apresentação $\mathbf{2 0}^{\circ}$ Congresso Brasileiro de Direito Ambiental - Meio ambiente urbano: uma construção interdisciplinar. SP: 25 de mai. 2015

MOREIRA, Ana Luísa Nogueira; ARAÚJO, Marinella Machado. Operações urbanas consorciadas no Estatuto da cidade. Disponível em: $<$ http://conpedi.org.br/manaus/arquivos/anais/campos/marinella_machado_araujo-

2.pdf>. Acesso em 10 jul. 2015.

MUKAI, Toshio. Estatuto da cidade. São Paulo: Saraiva, 2001.

OCTAVIANO MARTINS, Eliane Maria. Curso de Direito Marítimo, volume I: teoria geral. 4. ed. Barueri: Manole, 2013.

PADILHA, Norma Sueli. Fundamentos Constitucionais do Direito Ambiental Brasileiro. Rio de Janeiro: Elsevier, 2010. 
PREFEITURA DE SANTOS. Porto. Disponível em: <http://www.santos.sp.gov.br/?q=conheca-santos/dados-gerais/37293-porto>. Acesso em: 08 jul. 2015.

- Lei Complementar $\mathbf{n}^{\mathbf{0}}$ 793/2013. Disponível em: <http://www.santos.sp.gov.br/>. Acesso em: 10 jul. 2015.

PRESTES, Vanêsca Buzelato. Plano diretor e estudo de impacto de vizinhança. Revista de Direito Ambiental (janeiro-março de 2005), p.80. Disponível em: <http://lproweb.procempa.com.br/pmpa/prefpoa/spm/usu_doc/vanesca2-pd-eiv.pdf $>$. Acesso em 12 jul. 2015.

PORTO, Marcos Maia; TEIXEIRA, Sérgio Grein. Portos e Meio Ambiente. São Paulo: Aduaneiras, 2001, p. 64/65.

SILVA. Francisco Carlos de Morais. Manual de Direito Portuário. Vila Velha: Above publicações, 2013.

SILVA, José Afonso da. Direito Urbanístico Brasileiro. $7^{\text {a }}$ ed., São Paulo, Malheiros Editores, 2012.

ULTRACARGO. 2015. Terminal de Santos. Disponível em: http://www.ultracargo.com.br/br/localidades/santos-sp. Acesso em: 15 jul. 2015.

VEIGA, José Eli da. Desenvolvimento sustentável: o desafio do século XXI. Rio de Janeiro: Garamond, 2010, p. 189.

WILLEMAM, Cyntia da Silva Almeida. Estudo de Impacto de Vizinhança: Um Instrumento para efetivação do direito fundamental ao meio ambiente equilibrado. Revista da Faculdade de Direito de Campos, Ano VIII, N 10, Jun. 2007. 